\title{
Opportunities and constraints of the participation processes in urban mobility planning: case studies in the city of Rome
}

\author{
A. Ferretti \& A. Tieri \\ Sapienza, University of Rome, Italy
}

\begin{abstract}
For a long time, public participation in urban mobility policies has been weak in Rome, confined to a technical practice. However, in the last few years, in the wake of new Master Plan participation rules and new EU funds for participatory processes, an increasing number of administrative districts called "Municipi" are developing a more participatory approach, particularly in the field of local urban mobility. Even if this has not led to the formal signature of a "Mobility Agreement" between the local Government and local associations, the movements of inhabitants and local associations have succeeded in developing a set of proposals, which are being influential for the development of local political programs and day-to-day mobility policies (about public and private transport, cycling and pedestrian mobility). In particular, this paper will show opportunities and constraints of the participation processes in urban mobility planning in two case studies comparing effects, achievements and participatory technical methods: the project "Sbilanciamoci per la Mobilità" in the historical I Municipio, promoted by "Casa della Città", the first experiment of an Urban Center in Rome; the participatory review of the Cycling Master Plan of Rome in IX Municipio. The paper analyses two aspects: 1 - The effects and results of these initiatives in central and local governance policies in the field of urban mobility, identifying to what extent decision-making processes are being reinforced, or weakened, by sharing the definition of objectives, different monitoring and revision processes. 2 - The role that appropriate participatory technical methods play within general urban mobility strategies at different scales, improving resources for technical assistance and for transparent process, reducing conflicts with local stakeholders.
\end{abstract}

Keywords: participation processes, urban mobility planning, governance, Rome. 


\section{Participation for a sustainable mobility in Rome}

The New Urban Development Plan for Rome (PRG) was carried out in 2001 to approach the problems of city planning on the basis of three fundamental systems: settlement, environment and mobility. All three elements show a strongly innovative approach, compared with the old plan (1962) and compared with today's Italian city planning in general.

In theory, the mobility system in the new Plan for Rome aims to be the most radical and significant innovation with respect to the traditional planning approach. Indeed, it goes to the core problem of the city's sustainable development in an effort to eliminate the roman "genetic" anomaly (anomaly shared with other Italian cities) and its difference from other European cities: the fact that the city has been expanded at a later date and without the support of an effective rail system, trusting blindly in road transport, and for the lack of an environmental system conceived as an "ecological network". As pointed out above, the new plan for Rome develops the three fundamental aspects of urban planning sustainability trying to integrate these items with the need for an energetic "railroad care" (Campos Venuti [1]), and of the involvement of citizenship to share goals and methods of the planned urban transformations. Despite good intentions, there are still many critical issues that prevent the realization of these Plan goals. First of all, the fragmentation of projects from the perspective of sectoral policies (town planning, public transport, and so forth), or from the perspective of the weakest population groups (the handicapped, the children, the elderly, and women), caused from the sectoralisation of technical and administrative skills. Secondly, the lack of a real participatory approach (a lack of Italian tradition) that began to take hold in various sectors, including transport, only for the spread of the European policies for the sustainable development of European Municipalities: such as Local Agenda 21 and the Participatory Budget. With these experiments it was possible to see how the sustainability of policies, in support of a more efficient and less-impact mobility system, is likely to be ineffective unless accompanied by processes of sharing with the citizens like it happens in those countries that have consolidated the participatory tradition in planning processes.

The article, focusing on the case of Rome, aspires to reach a general conclusion: the participation, even in the planning of solutions belonging apparently to a "technical domain", is an element to assure of sustainability of a project (Sandercock [2]), in redefining a new vision of "good city" (Fusco Girard et al. [3]).

\section{The role of European policies in the sustainability and experimentation of processes of local governance in Rome}

The diffusion of Local Agenda 21 programs, as the Participatory Budgets experiences in Italy, has had over the last ten years a slow but steady growth differently distributed in the territory. There are many reasons. Firstly, the Italian cultural delay to incorporate concepts like sustainability and participation in 
environmental policy and, secondly, the lack of concreteness of the related policies at a national level (Belli [4]). For example, in the National Plan for Sustainable Development Agenda 21 (1993), the processes of Local Agenda 21 were not referred even if they represent the operative implementation of local policies for sustainable development. Moreover, there are difficulties of the Italian political system and of the administrative agencies to transform administrative practices, which still acting on the territory with sectoral approaches concerning environmental policies, and to introduce innovative mechanisms in terms of participatory tools and techniques aimed to share responsibilities and choices between technicians, politicians and citizens. In this sense, the issue of mobility is a typical example of the shortcomings present in the Italian development policies (which should be understood as a complex issue and really shared with the citizens) which caused many conflicts at both a national scale (e.g. the conflicts related to the implementation of the high speed train infrastructure TEN-T in Val di Susa) and locally, often ideological and a priori by all involved parties. In this scenario, suggests Morrison [5], the real solutions to overcome possible conflicts are related to the implementation of an "ecological democracy" able to find a solution, socially sustainable, to go beyond the current conflict between technology and democracy.

The case of Rome fits well in the framework outlined, although in 1995 Rome was one of the first Italian cities to join the European Sustainable Cities and Towns Campaign and signed the Aalborg Charter (1994), taking specific commitments regarding the sustainability of urban policies.

The enhancement process of local government and of participatory citizen agencies has strengthened the role of the institutions closer to citizens through the implementation of Local Authorities in 2000 and consolidated by the reform of Title V of the Constitution in 2001.

The city of Rome - the first in Italy - transformed its wards into 'Municipi', with a certain level of autonomy in decision-making on some sectors of expenditure and a directly elected chairperson for executive councils. The 'Municipi', however, does have not economic and financial autonomy from the choices of the Municipality of Rome. This dependence has triggered the search for extra funds, particularly European funds, to be allocated to specific projects through the promotion of Local Agenda 21 and of Participatory Budgeting practices, connected to participative programs on issues of urban sustainability and in particular of sustainable mobility with many limits (Allegretti and Herzberg [6]).

Participatory Budgets are participatory practices that involve citizens in the construction of policies and/or territorial projects based on the sharing of some expenditure items that make up the budgets of local authorities, developed from the experience Brazilian Porto Alegre (2000).

While for a Local Authority, participatory budgeting is a real possibility of having ad hoc funding to invest in sustainable policies promoted locally with citizens, on the other, the process is strongly influenced by the Municipality of Rome and cannot develop completely by itself. Secondly, the competences of the 
'Municipi' are limited, in particular with regard to investment and public works for road maintenance and the maintenance of schools and public buildings.

\section{Case studies}

\section{1 "Sbilanciamoci per la mobilità", example of participatory budget carried out in the Center of Rome}

In the First Municipio - which includes the Center of Rome - over several years of experiences of participation, born on the initiative of the cultural associations and of residents, have been developed and collected by the Municipio administration that has tried to involve them into a project coordinated from Sapienza University of Rome. The experience that has given rise to this path was that of the "Laboratory on land use choices", a permanent workshop to discuss the new Plan of Rome and evaluate its effects on the sensible context (social and historical-architectural) of the Historical Center, increasingly specialized commercial for tourism and for the tertiary sector and less suitable for residence.

The participatory agency, not institutionalized, worked from 2003 to 2008 and has started up many concrete projects on sustainable mobility issues and on the promotion of cycle-pedestrian mobility in the historical areas, and on the employment of public land by commercial activities.

The first of these projects is the program "Sbilanciamoci for the mobility in the Historical City": a form of application of methods for participatory budget to elaborate of the 2006 Investment Plan and related projects (note: the use of the Italian word 'sbilanciare' is a pun because it means at the same time 'imbalance", 'out-of-budget' and 'risk'; so the sense of title of the project could be freely translated in English as 'We accept the risk of using a local budget for improving the mobility in the Center of Rome'). The second one is the "Casa della Città" (House of the City), with the role of involving citizens to share information, objections and proposals about the transformation of the city (an agency provided by the Regulations on the participation of the Plan of Rome but never truly operational). The First Municipio's experience is a pilot experience unique in the Municipality of Rome.

The issue of mobility has always been fundamental and widely debated between citizens, politicians and technicians. During the public debates very different opinions indeed emerged on Municipality of Rome's policies regarding the strengthening of public transport in the Historical Center. On the one hand, in fact, there was a wide agreement about the pressure caused by private mobility on the central areas, which could be reduced by effective policies to support local public transport. Across the issue of strengthening of the Rome subway lines (for reducing environmental impact of this strengthening, see Malavasi et al. [7] and Ricci and Presta [8]) and new stations in the central areas proposed by the City in the "Pact for the mobility of Rome" in 2003 (guidelines presented in the new Master Plan of Rome), has caused conflicting reactions. All controversial issues such as the subways in Rome, and the closing of the Roman Fori, have been discussed extensively in the Laboratory and the results of debates have been 
presented in public occasions such as "open questions". The discussion of the Parking Plan of the City of Rome (also in 2003) has revealed widespread awareness that to ensure true quality of life of residents, and to solve the critical problem of traffic in the Center, it would be necessary to act on different aspects and on different scales: reducing the number of parking permits in the limited traffic zones (nearly seven hundred more in a year) and the permits for the occupation of public land.

In the program "Sbilanciamoci for mobility in the Historical City" the First Municipio has explicitly shared with the citizens, during 4 months of work, priorities and financial and planning choices related to the Investment Plan (2006) regarding road maintenance and upgrading of public spaces.

Inspired by the experience of the Participatory Budget made in Porto Alegre (the first trial in this context) the objectives of the process were:

- to develop a process to influence the choices of First Municipio;

- to enable and support active citizenship paths.

The public invitation was an opportunity to develop a comparison not only on extraordinary maintenance (to be included in the 2006 budget), but also more broadly on issues of viability. Project proposals could then refer to:

- the repaving of road foundations and landscaping;

- the organization of vehicular traffic, pedestrian and street furniture.

The former focuses on the redesign and physical arrangement of the road and sidewalks, with an indication of materials to use and works of street furniture that are considered useful to the objectives set (wild bollards for parking, speed bumps to reduce speed, etc).

The second concerns the reorganization of traffic, both pedestrian and vehicular, as - for example - change of accesses to the streets and directions of travel, indicating lanes, pedestrian squares and paths, etc.

The basic choice was to articulate the territory of the historical areas into nine geographical areas, rather homogenous, defined primarily on the basis of local perception and traditional division, with the goal of arriving at the identification of priorities for each area. Figure 1 shows the nine areas.

The project ideas received from citizens, despite the limited time, were almost 70. There were 23 proposals (for a total of 30 project ideas, because every proponent could advance up to three project ideas per proposal) and 29 working reports (for a total of 39 signs) elaborated with technicians, citizens and elected local representatives. The working group of the University has considered both proposals, reports and many comments. Thematic workshops for each focus area of the historical center have been organised and there has been a selection of the best proposals which attention has been concentrated on in the following phases. The Laboratory (citizens, technicians and local representative elected) have been working to elaborate a final proposal to integrate all the proposals received. Public discussion was then started. 


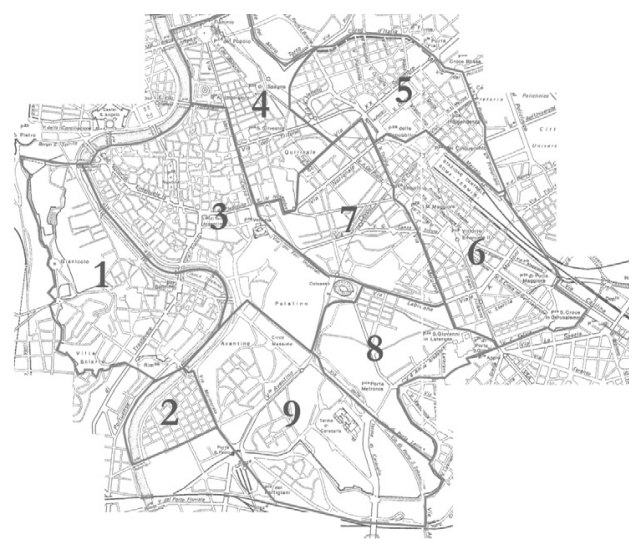

Figure 1: $\quad$ Priority historical areas of 'Sbilanciamoci' project: 1) Trastevere; 2) Testaccio; 3) Quartiere Rinascimento: 4) Tridente e Trevi; 5) Sallustiano - Castro Pretorio; 6) Esquilino; 7) Monti; 8) Celio; 9) Aventino - San Saba.

The main steps of the project "Sbilanciamoci" are:

- the definition, organization and launch of the initiative (through a public invitation to put forward ideas and proposals);

- the participatory process linked to the formation of the Investment Plan (primarily through workshops open to all citizens and public administrators, and then with site surveys, aimed at a better definition of integrated projects, to their economic size, to the identification of a grid priority, to the feasibility check, to the formulation of proposals for the budget scheme, etc).

- the selection of a participatory project for each of the nine geographical areas included in the 2006 Budget of the Historical Center;

- a participatory workshop to support the development of municipal opinion on the proposal of the municipal budget, with appropriate reasons and arguments (in terms of design choices, contextualization of intervention compared to the urban reality, priorities to be assigned to a possible action plans);

- the selection of proposals by the Municipality of Rome, in the finalization of the 2006 Budget: five projects have been funded according to the financial resources provided and not according to quality standards or other criteria;

- start-up of participatory process on stages from the commitment of expenditure to realization (and hence on the design and implementation of the works);

- monitoring of the achievements on the timing and quality of interventions.

Four projects were excluded from the financing of the City, but two of these were later implemented with funds allocated from the First Municipio itself, and through coordination with the VII Department of the City Hall for mobility.

From the five projects funded in 2006, the "Plan of participatory interventions" has developed the "Guidelines" for the engineering design of interventions, acknowledged to the Municipio technical offices and this allowed 
a first access to the Participatory Budget funds of First Municipio. Furthermore, the program has achieved the following objectives:

- developing and improving relations between the institution and between citizens and municipal technical areas and inhabitants;

- describing policies and decisions more concrete and useful to the municipal technicians through the contribution of ideas and proposals of citizens;

- encouraging active citizenship, urging and supporting bottom up initiatives to improve and encourage empowerment of citizens.

\subsection{Observations on the Cycling Plan of Rome in IX Municipio}

The considerations presented here are the results of the participatory process developed under the project of IX Municipio's Local Agenda 21 on the issues listed below:

- discussion (gathering information and observations) on the San Lorenzo Urban Project - Vallo Rail - Inner Ring Road. A preliminary planning scheme prepared and proposed by the City of Rome;

- discussion of the Urban Parking Plan of the Municipality of Rome in the IX Municipio has made a formal request for an injunction;

- discussion (information and collection of observations) on the Cycling Plan of the City of Rome;

- the close examination of mobility issues and green network at a local level.

For this purpose, the Municipio has been divided into four areas of reference.

To support the process of participation inherent in the activities of the Agenda 21 Forum have organized seminars and public meetings at the municipal level with the help of experts (especially on issues of public transport and environmental pollution). The critical issues and resources were identified in the thematic workshops for each geographical area of reference. The results have been mapped in thematic maps prepared with the collaboration of the residents (see figure 2).

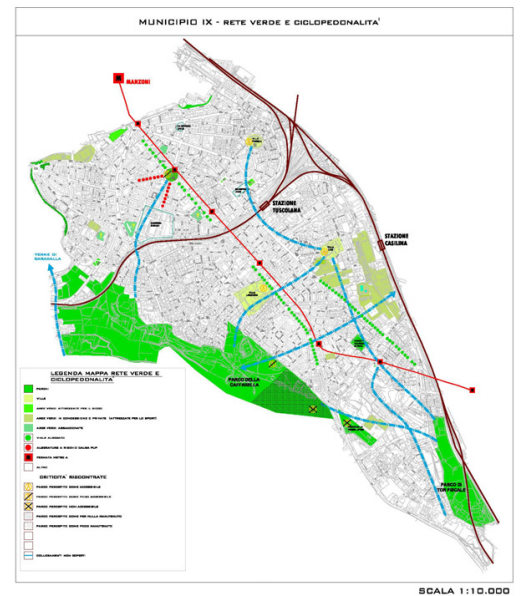

Figure 2: $\quad$ Example of thematic map on the cycling plan and green network. 
The Agenda 21 process began on June $9^{\text {th }} 2010$ and involved about 100 inhabitants who were very active in the field of sustainable mobility and cyclemobility, for a month and a half of intense work. Thanks to their active contribution, it has been possible, within the agreed time, to implement a document of proposed revisions and improvements of the Cycling Plan submitted by the Municipality of Rome. This document synthesizes and integrates objectives and proposals of various associations of resident cyclists and on the Roman territory.

Main problems that emerged in the participatory process are connected to the fact that the existing $225 \mathrm{~km}$ of cycle paths in Rome have a strong fragmentation caused by the lack of connections between dorsal main paths that prevent the realization of a cycle network that is really functional to the mobility demand.

The strategic policies of the new Framework Plan for Cycling of Rome treats the use of bicycles only for leisure through the green urban areas. There are general critical issues:

- a lack of connection paths between the local centralities (universities, schools, public offices, etc) that could be built with minimal cost, making little changes to the sidewalks or roadway providing an adequate level of safety and comfort; - a lack of an effective mobility network to link different areas of the city directly or through inter-modal nodes with public mobility;

- the adjustment of public transport vehicles for the service of bicycles on board;

- maintenance of existing and planned trails, which should be designed with a specific maintenance plan from the characteristics of the area, involving local associations of resident cyclists;

- a lack of appropriate crossings, checked by special traffic signals and pedestrian facilities, or dedicated (on request) to prevent occasions for danger;

- the upgrading of signage along the bike paths (e.g. obstacles to the normal movement, the poor lighting and the absence of SOS along the route);

- a real assessment of the economic feasibility of planned actions and lack of a credible agenda of interventions.

In general, what has emerged strongly from the meetings between citizens and technicians is that they do not want to create paths for "professional cyclists" but fit to be shared with pedestrians, disabled, parents with prams and older people wishing to walk in true and proper oasis, with a limit of $20 \mathrm{~km} / \mathrm{h}$ for the bikes.

The synthesis and analysis of proposed solutions is shown in the graph of figure 3, which illustrates the different policy areas considered strategic for achieving a sustainable system of mobility cycling in the IX Municipio:

- The system of relations between the main network cycling and local. The objective is to reconnect the local centrality among themselves and with those of urban areas, with green corridors and with railroad network. To achieve a truly alternative mobility is necessary to resort to the creation of fast paths, alternatives to the corridors available in the parks (and thus bound to the hours of opening to the public). These corridors should be preferably tangential to the Municipio and connected to the main crossing axes. 
- A system of a main cycling network at a local level that relies on two main axes (vertical and horizontal) crossing the territory with a certain eccentricity to improve the existing network. The realization of these two axes is considered a priority because it allows you to create an alternate connection to the car in an area characterized by its great size and besieged by the relevant traffic.

- The reconnection of the parks in the area. This in manner to appreciate the natural and archaeological resources present, unique in urban areas.

- The testing of some areas at a low speed. The "zones 30" identification was only qualitative in the absence of time to explore the topic and project. For some areas, this could be identified along the route for the construction of bike paths which may be only for signage cost, at no extra cost to bring the roadway to the mixed traffic of bicycles and motorized vehicles.

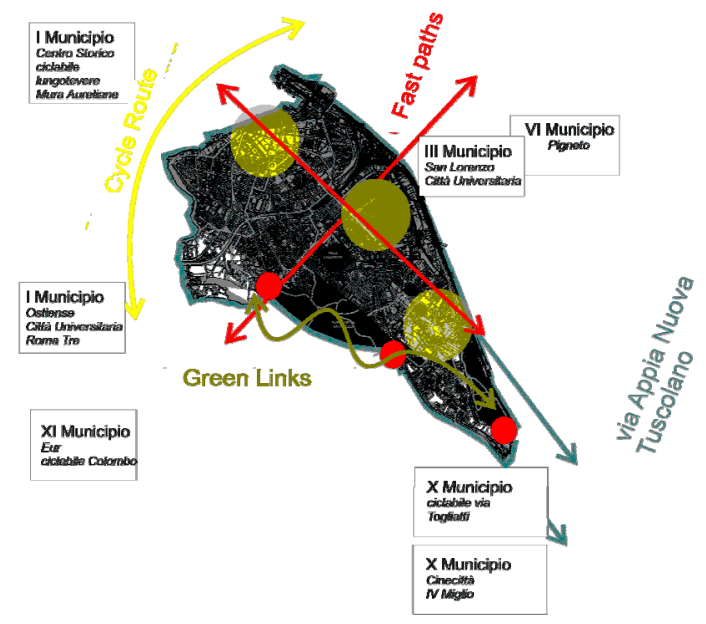

Figure 3: Cycle Mobility of IX Municipio proposed by participatory process.

\section{Discussion on case studies: opportunities and constraints of the participation processes in urban mobility planning}

The case studies show the relationships among urban structures, European programmes related to sustainable development, and transport problems from the point of view of the residents. In particular, these experiences of transport policies have been more effective because of the impact of land use, urban activities and the administrative systems have been taken into account at the same time, rather than choosing an approach focusing on the transport issue.

The principle of susbsidiarity is a main key to give an appropriate distribution of roles between the technical approach, political choices and point of view of the citizens. As the cases show, the most important opportunities are related to 
the methodological guidelines for sustainable mobility policies that can be summarized in the following key-words:

1) Links between actors, knowledge and powers (technical and political) to share the strategic choices of urban planning beyond the perspective of sectoral approaches (town planning, public transport, and so forth);

2) Integration of the urban policies and projects to improve the sustainable development and the quality of life both in the Center and in suburban areas;

3) Continuity of relationship between residents, technicians and elected representatives to give continual feedback about sustainable effects (or not) of urban policies on everyday life;

4) Decentralization of policies related to sustainable issues and of financial fund to complete the local participatory processes related to specific European programmes.

5) Co-participation in the management of infrastructure for sustainable mobility to strengthen the links between institutions and territory and to involve the citizens in the implementation of sustainable policies.

\subsection{Main constraints emerging from the case studies}

The question of the effectiveness of participation is a problem for elected local representatives and technicians. There is no agreement as to the answer to this question and the parameters used in evaluations are often different. In fact, effectiveness depends, to a large extent, on the political aim of a participatory system.

Often the technicians and politics look at cities only - or especially - from the perspective of sectoral policies (town planning, public transport, and so forth), or from the perspective of the weakest population groups (the handicapped, the children, the elderly and women). This tendency to divide into segments is shared by those who are often involved in the area of participation. This can be a problem because it causes a dichotomy between policy and participation and between participation and results. First of all, the gap between the timeframe of local residents and the timeframe of politicians are parameters which impact on the practices and depend to a large extent on the local context, despite the fact that the problem is common to all the practices studied. This can often lead to a gap between expected results and real results for the following reasons:

- strong tension and contradictions between the participation timeframe and the timeframe of technicians and politicians;

- absence of a common language among the key-actors (citizen, technicians, elected representatives) of a given process.

A common base is necessary to mutually build ideas and projects. It would also be useful to simplify the terms used by technical experts and elected representatives. The level of the resident language can also be raised (this last point needs further discussion, as this would involve raising the level of qualification of citizen which is one of the most important goal of a participatory practice). Many local technicians and civil servants are asking to be trained in participatory methods and this would be an opportunity to break down the too 'techno-centric' vision. Instead, the principle of training citizens to create a 
hybrid figure of "technical citizen" useful to speak the language of the experts in participatory projects is debatable.

Based on the results of cases studies, two approaches have emerged: one involves training the residents, while the other suggests a process of joint training of all the participants, citizens, technicians and local representative elected.

\subsection{The relationship between participation and non-participation is a problem that needs to be addressed}

It would be useful to find a meeting point in which policies can join the demands of participation and the whole territory, far from the two extreme situations: setting up a workshop in response to every problem or choosing always a topdown process to define strategies of urban planning. The point is not necessarily to institutionalise participation, but rather how to develop a truly participatory policy. Some citizens do not want to be forced to participate, and this is what the institutionalization of participatory structures often leads to. Moreover, institutionalization seems to make little difference in the degree of participation and in its quality: on one hand, the empowerment of stakeholders is a good starting point for participatory policies but, on the other, projects developed over a long period and in consultation with peripheral stakeholders, frequently turn out to be less expensive than projects designed by technicians. This problem can be solved by expanding participation to include non-organised citizens and for this reason, the dynamics of promotion of information are crucial and need a specific communication plan: to inform, raise awareness and involve. In some cases, the presence of strong local reference groups may support the start-up of institutional participation process in its early stages.

\section{Conclusion}

The participation can frequently lead to conflict. So the concept of sharing is important as a prerequisite for citizens, technicians and elected local representatives to cross the barriers of preconceived ideological positions: sharing of goals, of the priority issues to be addressed, of rules, etc. It is a fact, instead, that when participatory bodies acquire credibility, the conflict disappears.

This is a critical point especially in the cases where there are unclear dynamics between private and public investment: a lack of articulation between various political and administrative agencies without real participation by residents creates problems when various decision-making agencies, participatory processes, or action areas are overlaid. This can lead, among other things, to a lack of social confidence in the local institutions and this is what happens most of the time. An example is the unclear link between private investment agencies and the Municipality of Rome. These estate agencies in the past (Insolera [9]) have guided the planning strategies and implementation of the new urban settlements. Even today, in implementing the projects of "urban centralities" 
provided by the PRG, it often happens that the construction of buildings is not preceded (nor followed for many years) the construction of the infrastructure network that connects the new settlement with the rest of the city.

Lastly, the most important challenge of participatory process is to define what strategies can be developed to link the participatory bodies with different levels of technical knowledge and of political level, above all to improve positive impacts of the process of participation on the sustainability urban policies related to transport, landscape and quality of life in general. But, it is obvious, at least to the experts of participation that the effectiveness of a process proceeds from its entire cycle. So only if a project is defined by the local population, by politicians and by the technicians, and only if it is funded, this represents a completed cycle, really sustainable: economically, temporally, and socially.

\section{References}

[1] Campos Venuti G., The mobility system, Urbanistica n.116, Rome, pp. 265-267, 2001.

[2] Sandercock L., Cosmopolis II. Mongrel Cities of the $21^{\text {st }}$ Century, Continuum, London, New York, 2004. ISBN 0826470459.

[3] Fusco Girard L., Forte B., Cerreta M., Del Toro P. \& Forte F., The Human Sustainable City: Values, Approaches and Evaluating Tools, Sustainable Urban Development, Vol. II, Routledge, pp. 65-93, 2007. ISBN 0-20341703-8.

[4] Belli A., Il territorio speranza: politiche territoriali possibili per il mezzogiorno d'Italia, Alinea, Firenze, 2002. ISBN 88-8121-575-8.

[5] Morrison R., Ecological democracy, South End Press, Boston, 1995. ISBN 0-89608-513-9.

[6] Allegretti G. \& Herzberg C., Between efficiency and local democracy growth: the challenge of Participatory Budgets addresses the European context, Transnational Institute - New Politics Project Working Paper n. 5, August 2004.

[7] Malavasi, G., Palleschi, P. \& Ricci, S., Driving and operation strategies for traction-energy saving in mass rapid transit systems in Proceedings of the Institution of Mechanical Engineers Part F-Journal Of Rail and Rapid Transit, September 2011, SN 0954-4097.

[8] Ricci S. \& Presta M., Planning, construction and experimental tuning of an urban railway noise cadaster in Proceedings of Urban Transport IX: urban transport and the environment in the $21^{\text {st }}$ Century - Advances in Transport - March 10-12, 2003, Iraklion, Greece, SN 1462-608X, BN 1-85312-961-5.

[9] Insolera, I., Roma moderna. Un secolo di storia urbanistica 1870-1970, Einaudi, Torino, 1993. ISBN 9788806159313. 